\title{
“Adonde é o aposento do pescado?": ecozoneamento do manguezal na pesca artesanal de crustáceos da Reserva Extrativista Marinha da Baía do Iguape, Maragogipe - Bahia
}

\author{
Francisco Santos Cousiño Casal* \& Francisco José Bezerra Souto
}

Laboratório de Etnobiologia e Etnoecologia, Departamento de Ciências Biológicas, Universidade Estadual de Feira de Santana, Av. Transnordestina, s/n, Novo Horizonte, 44036-900, Feira de Santana, Bahia, Brasil.

\begin{abstract}
Resumo - Os crustáceos, juntamente com os moluscos e peixes, correspondem aos recursos pesqueiros mais importantes para a subsistência e renda de populações humanas em ecossistema de manguezal. Nesse ambiente, sistemas culturais tradicionais reconhecem e classificam determinadas áreas ecológicas denominadas ecozonas. O objetivo deste trabalho foi compreender como os pescadores caracterizam as áreas de pesca e como estes conhecimentos tradicionais influenciam na pesca artesanal de crustáceos no ambiente de manguezal. O estudo foi realizado na Reserva Extrativista Marinha da Baía do Iguape, com a comunidade de pescadores do Angolá. A amostra dos informantes foi definida a partir de indivíduos oportunisticamente encontrados e pelo critério de especialistas nativos. Realizaram-se entrevistas abertas e semiestruturadas com 42 pescadores. Também foram utilizadas técnicas de turnês guiadas e de mapeamento participativo. As principais zonas ecológicas identificadas pela comunidade pesqueira do Angolá foram: costeiro, riacho, rio, boca de rio, enseada, canal, coroa, poço, ilha, ilhote, mangue e terra. Os pescadores do Angolá demonstraram ter um aguçado domínio da espacialidade dos sítios de pesca e suas características e uma classificação consistente das ecozonas, relacionando-as aos aspectos bioecológicos dos recursos pesqueiros explorados.
\end{abstract}

Palavras-chave adicionais: conhecimento tradicional, Decapoda, ecozonas, mapeamento participativo.

\begin{abstract}
Mangrove ecozonation in artisanal fishery of crustacea of Marine Extractive Reserve of Baía de Iguape, Maragogipe, Bahia, Brazil) - Crustaceans, along with molluscs and fish, are the most important fishing resources for subsistence and income for people in the mangrove ecosystem. In this environment, traditional cultural system recognize and classify certain ecological areas called ecozones. The aim of this study was to understand how the fishermen characterize the fishing areas and how this influences the traditional knowledge of the artisanal fishing of crustaceans in the mangrove ecosystem. This study was carried out at the Baía de Iguape Marine Extractive Reserve, with the fishing community of Angola. The sample of interviewed was defined from individuals opportunistically found using the criterion of native experts. There were open and semi-structured interviews with 42 fishermen. Techniques of guided tours and participatory mapping were also used. The main ecological zones identified by the fishing community of Angola were: "costeiro" (= coastal), "riacho" (= stream or creek), "rio" (= river), "boca de rio" (= river mouth), "enseada" (= creek), "canal" (= waterway), "coroa" (= shoal), "poço" (= well), "ilha" (= island), "ilhote" (= islet), "mangue" (= mangrove) and "terra" (= land). The Angola fishermen have demonstrated a refined spatial knowledge about fishing sites and their features, relating them to bioecology of fishing resources exploited.
\end{abstract}

Aditional key words: Local knowledge, Decapoda, ecozone, participative mapping.

Os crustáceos, juntamente com os moluscos e peixes, formam o conjunto de recursos pesqueiros mais importantes para a manutenção de populações humanas em ecossistemas de manguezal (Severino-Rodrigues et al. 2009). Os grupos mais familiares pertencem aos Decapoda, contendo uma grande diversidade de caranguejos e de camarões. Dentre os braquiúros semiterrestres e exclusivos de manguezal, destacam-se as espécies Cardisoma guanhumi (Latreille, 1825) (Gecarcinidae), Ucides cordatus (Linnaeus, 1763). (Ocipodidae), Goniopsis cruentata (Latreille, 1803) (Grapsidae), que juntamente com os siris do gênero Callinectes representam um importante potencial pesqueiro e alimentar ao homem (Fontes et al. 2008), apesar da contínua diminuição dos estoques e redução do tamanho dos

*Autor para correspondência: tituscasal@gmail.com

Editor responsável: Rômulo Romeu Nobrega Alves

Recebido: 16 maio 2011; aceito: 6 set. 2011. espécimes (Amaral \& Jablonski 2005).

A captura de recursos pesqueiros é uma das atividades mais antigas exercidas pelas sociedades humanas, em período anterior ao Neolítico, tendo uma importância não somente econômica, mas cultural e simbólica (Diegues 2004). De acordo com este autor, em determinadas épocas, sociedades inteiras dependiam quase exclusivamente da pesca, servindo-se do ambiente aquático como fonte de alimento e meio de comunicação, assim como ainda é possível observar em algumas comunidades pesqueiras.

Os pescadores artesanais, tanto de água doce como marinhos, não procuram as suas presas ao acaso, mas buscam em locais específicos em ambientes aquáticos. Em termos ecológicos, tal comportamento não surpreende, visto que na natureza os organismos também não estão distribuídos uniformemente, mas sim em aglomerados (manchas) (Begossi 2004). Registros da identificação e 
nomeação destes locais têm se mostrado comuns em trabalhos etnoecológicos, tendo em vista que isto permite uma efetiva comunicação dos profissionais da pesca entre si. Ainda assim, são poucas as pesquisas que se debruçaram especificamente sobre este tema (Souto 2010). Posey (1987a) empregou o termo "ecozonas" para indicar essas áreas ecológicas reconhecidas em sistemas culturais tradicionais.

O presente estudo objetivou compreender como os pescadores caracterizam as áreas de uso pesqueiro e como estes conhecimentos tradicionais influenciam na dinâmica da pesca artesanal de crustáceos no ambiente de manguezal.

\section{MÉTodos}

Área de estudo. A Bahia possui um dos maiores perímetros de costa do litoral brasileiro, distribuído ao longo de mais de $1.100 \mathrm{~km}$ (Ramos 2002). Neste, merece destaque a Baía de Todos os Santos (BTS), a maior baía do território nacional, que pode ser considerada um grande complexo estuarino-lagunar, incluindo um conjunto de várias ilhas e núcleos urbanos no seu entorno (Almeida 1997).

A BTS possui litoral articulado com enseadas e pequenas baías (Diegues 2002). Dentre estas, está a Baía do Iguape, que compõe um complexo sistema hídrico formado pelo encontro das águas dos rios Guaí e Paraguaçu - este de maior influência - e cercado por frondoso e extenso manguezal, abrigando a diversidade de vida da fauna e flora locais (Ramos 1993; Brito 2001; Santos 2008), sendo por isso, bastante utilizada por numerosas comunidades extrativistas. Neste contexto, foi criada, em agosto de 2000, através de decreto federal, a Reserva Extrativista (RESEX) Marinha da Baía do Iguape (Figura 1), abrangendo uma área de 8.117,53 ha, dos quais 2.831,24 ha correspondem a terrenos de manguezal e 5.286,29 ha de águas do interior da baía, nos municípios de Maragogipe, Cachoeira e São Félix (Recôncavo Baiano), com a finalidade de garantir a exploração autossustentável e conservação de recursos naturais utilizados tradicionalmente por parte daquelas comunidades (IBAMA 2000).

Maragojipe é reconhecidamente uma importante área de extração de recursos pesqueiros (pesca e mariscagem) do estado da Bahia (Bahia Pesca 1994), abarcando dezenas de comunidades pesqueiras. Dentre estas comunidades está o Angolá, localizada na periferia da sede municipal da cidade (12 $46^{\circ} 42.08^{\prime}$ 'S, $\left.38^{\circ} 55^{\prime} 8.75^{\prime \prime} \mathrm{W}\right)$. Seus moradores vivem majoritariamente da extração e comercialização dos recursos pesqueiros do Iguape, com destaque para a captura de crustáceos das extensas áreas do ecossistema de manguezal que circunda a cidade.

Procedimentos de coleta e análise de dados. Inicialmente, o projeto proposto foi submetido à comunidade, que aceitou o trabalho através da assinatura de um Termo de Anuência. O ponto de partida na coleta de dados se deu através da identificação de um informante- chave, morador da comunidade, que indicou outros informantes, permitindo assim a ampliação da amostra por bola-de-neve (snowball; Bailey 1994). A amostra dos informantes é apoiada pelos trabalhos-referência para esta pesquisa de Marques (2001) e Souto (2004), onde os sujeitos são indivíduos "oportunisticamente encontrados" e pelo critério de "especialistas nativos", quando estes se autorreconhecem e são reconhecidos pelos membros da comunidade como competentes no desenvolvimento das atividades de pesca.

Inicialmente, foram realizadas entrevistas livres, a medida que ia se conhecendo os sujeitos envolvidos na pesca artesanal dos crustáceos. As entrevistas livres tiveram caráter de não-especificidade - com intuito de conhecer aspectos mais gerais da comunidade local, do ecossistema de manguezal e da ação dela sobre este a partir das práticas de extração dos recursos, permitindo ao pesquisador assimilar a forma de se comunicar, juntamente com as expressões típicas da comunidade. Progressivamente, atingiu-se um ponto de confiança mútua entre pesquisador e pesquisados (rapport) que foi fundamental para uma boa inserção no ambiente de pesca e, consequentemente, para uma eficiente obtenção de informações.

As entrevistas foram precedidas por apresentação do pesquisador; esclarecimentos do caráter do projeto, incluindo seus objetivos, métodos e possíveis benefícios à comunidade; e posterior pedido para gravação. Esse procedimento foi realizado a partir da leitura e assinatura do Termo de Consentimento Livre Esclarecido (TCLE), seguindo normas do Conselho de Ética em Pesquisa da Universidade Estadual de Feira de Santana.

Posteriormente, entrevistas semiestruturadas direcionaram as indagações para temáticas mais específicas, sendo amostrados 42 pescadores. A amostra foi considerada suficiente quando atingiu-se o ponto de saturação (Berteaux 1980, apud Santos \& Santos 2008), no qual o pesquisador percebe não apreender dados novos sobre o objeto de estudo durante as entrevistas. As entrevistas gravadas foram transcritas verbatim, resguardando o enfoque êmico preconizado pela etnobiologia de Posey (1987a,b).

A partir de observações diretas (Stebbins 1987), realizaram-se registros enquanto os pescadores estavam em atividades referente ao cotidiano da pesca. Esta técnica equivale a do observador não-participante e não-membro, que garante o distanciamento científico apropriado para a validação da pesquisa (Marques 2001).

Turnês guiadas pelos próprios pescadores (Grenier 1998) foram realizadas nas áreas de extrativismo durante as atividades de pesca. Essa ferramenta apresentou grande importância para a pesquisa, pois auxiliou o pesquisador na familiarização com as áreas e pontos de pesca (Begossi 2004) frequentados pelos pescadores e constantemente citados durante as entrevistas.

Para mapear a área e os pontos principais de utilização pelos pescadores, adotaram-se mapeamentos participativos 


\section{MINISTÉRIO DO MEIO AMBIENTE
INSTITUTO BRASILEIRO DO MEIO AMBIENTE
E DOS RECURSOS NATURAIS RENOVÁVEIS}

Reserva Extrativista Marinha Baía do Iguape / BA
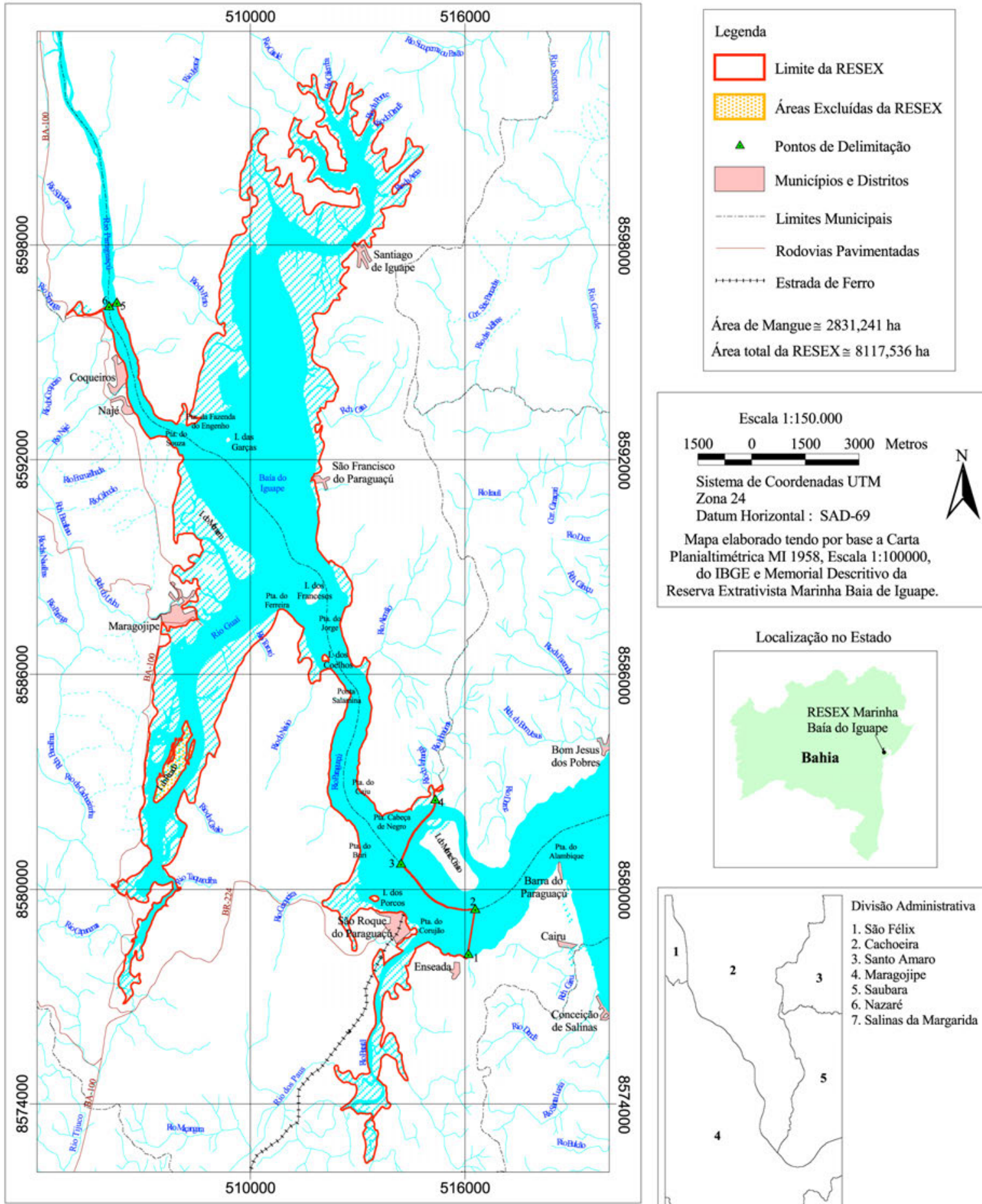

Mapa elaborado tendo por base a Carta Planialtimétrica MI 1958, Escala 1:100000, do IBGE e Memorial Descritivo da

Reserva Extrativista Marinha Baia de Iguape.

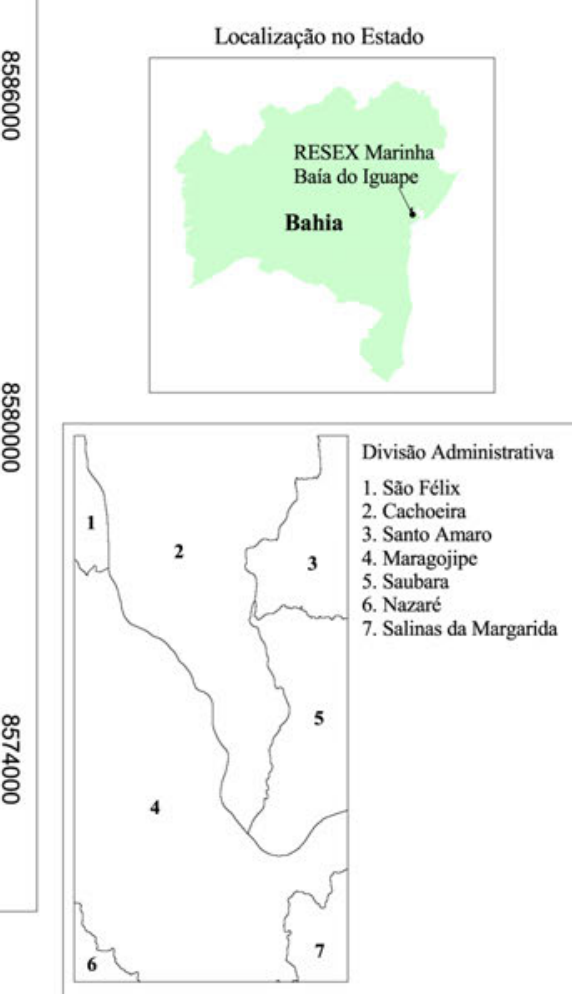

Figura 1. Mapa da RESEX Marinha da Baía do Iguape, Maragogipe, Bahia (IBAMA/CNPT). 
coletivos (Faria \& Neto 2006), objetivando, além da construção de um mapa das áreas de extração dos recursos pesqueiros, discussões proporcionadas por este, onde características dos ambientes e da biologia e ecologia dos animais pescados puderam ser aprofundadas. Os dados obtidos foram analisados qualitativamente pela abordagem emicista/eticista, comparando conhecimentos tradicionais (êmicos) e os correspondentes na literatura acadêmica (éticos) (Feleppa 1986).

\section{Resultados e Discussão}

Oito espécies foram identificadas, dentre os principais crustáceos comercializados pelos pescadores da comunidade do Angolá, e estão agrupadas da seguinte forma: caranguejo (Ucides cordatus); aratu (Goniopsis cruentata); guaiamum (Cardisoma guanhumi); siris: siritinga ou siri-de-coroa (Callinectes danae Smith, 1869) e siri-açu ou siri-de-mangue [Callinectes exasperatus (Gerstaecker, 1856)]; e camarões: camarão-branco [Litopenaeus schmitti (Burkenroad, 1938)] camarão-duro ou camarão-coroeiro [Farfantepenaeus subtilis (PérezFarfante, 1967)] e camarão-vermelho [Xiphopenaeus kroyeri (Heller, 1862)].

De acordo com o conhecimento local, estes crustáceos relacionam-se com distintas unidades de paisagem encontradas ao longo do estuário da Baía do Iguape. As unidades, que permeiam o espaço da pesca e estão associadas aos crustáceos, identificadas na comunidade pesqueira do Angolá foram: "canal", "costeiro", "enseada", "poço", "coroa", "mangue", "terra", "boca de rio", "rio", "riacho", "ilha" e "ilhote" (Figura 2). Nos estudos de Souto (2010), pescadores de uma região da BTS também identificaram algumas ecozonas (costeiro, rio, enseadas, canais, ilhas, mangue, coroas e mar aberto) com nomenclaturas e aplicações similares para o ambiente de manguezal, porém com algumas diferenças claras que podem se justificar devido às características peculiares de cada baía e do sistema cognitivo das comunidades.

De acordo com a descrição dos informantes locais, o "canal" é a parte mais larga e profunda da Baía do Iguape, onde permanece com água mesmo nos períodos de baixamar, sendo sempre navegável com a canoa, embarcação mais usual. É também o local onde os pescadores desenvolvem a maior parte das atividades ou por onde passam ao se direcionarem aos sítios de pesca: "[...] no canal todo aí pesca." Não há como os pescadores do Angolá se dirigirem para qualquer ponto de pesca na outra margem da baía, sobre sua embarcação, sem antes ter que atravessar esta ecozona. Esta pode ser uma explicação porque o canal é uma das zonas mais citadas durante as entrevistas e as observações diretas na pesca, principalmente pelos pescadores de camarão, já que estes crustáceos abundam nesta ecozona, notadamente as espécies Litopenaeus schmitti e Farfantepenaeus subtilis.

Souto (2010) também registrou canais, descrevendoos como sulcos mais fundos, que nunca secam totalmente, sendo mais frequentados por pescadores de camarão. Porém, diferentemente do seu estudo, que apresentou vários canais distintos, na Baía do Iguape existe apenas um grande canal que, em uma determinada região do seu curso, divide-se e recebe nomes distintos: Canal do Meio e Canal de Fora.

Os "costeiros" são áreas próximas da margem do canal, que se encontram com a vegetação de mangue ("O $\underline{\text { costeiro }}$ é próximo ao mangue.") e que durante a baixa-mar costuma permanecer descoberto. São bastante utilizados pelos pescadores de siris, que durante as marés ditas "pequenas" (quadratura), colocam as armadilhas para o siri-açu, já que a água não adentra as áreas de mangue e os artefatos (munzuá) precisam ser recobertos pela maré: "Maré pequena, botador de munzuá só bota pro siri-açu no costeiro, porque a maré não toma mangue."

Outra zona de importância na navegação dos pescadores com canoa e na captura de camarões e siri-decoroa é a "enseada", apresentando uma reentrância em direção à costa, em um formato côncavo: "enseada a gente chama onde tem essas curva assim." Nos períodos de baixamar, uma extensa área de substrato permanece descoberta, sendo novamente coberta após a enchente da maré: "Chama enseada porque ela vaza muito." Com isso as "enseadas" podem formar extensos "costeiros" nas marés baixas ou integrar o "canal" nas marés altas. Este é um dos exemplos que fortalecem a premissa de Souto (2010), de que as ecozonas não apresentam separações bruscas entre si, podendo haver sobreposição, áreas de transição ou mesmo estarem inseridas uma nas outras. Por também perceber isto entre os índios Kayapó, Posey (1987a) registrou zonas ecológicas, subzonas e categorias de transição, dependendo das características. Souto (2010) identificou as enseadas como uma unidade espacial caracterizada pelos pescadores por apresentar sedimento de fundo lamoso e serem as principais áreas para pescas de camarões e peixes. $\mathrm{O}$ termo também foi registrado entre pescadores em um estuário no sul da Bahia (Cordell 1974).

$\mathrm{Na}$ enseada, também está inserida outra ecozona, conhecida como "poço". Segundo pescadores, são áreas mais profundas no interior da baía, escavadas pela correnteza das águas ("[...] porque a carreira da água cava os poços."), com aproximadamente 10 braças, ou seja, cerca de $15 \mathrm{~m}$ : "Aqui na enseada tem um poço. Tem um poço mermo, já é mais fundo que o meio do canal." Os poços são comumente referidos como locais de refúgio de camarões e peixes, sendo inclusive utilizados nos períodos reprodutivos: "Adonde é o aposento do pescado?... Que nem o camarão que vai desovar, adonde vai ficar aqueles filho? No poço."

As "coroas" são bancos mistos de areia e lama ("Tem a outra lama que já é areada, que é o lugar da coroa.") que geralmente emergem durante o período de baixa-mar: "Aí chama coroa porque? A maré passa de um lado e de 

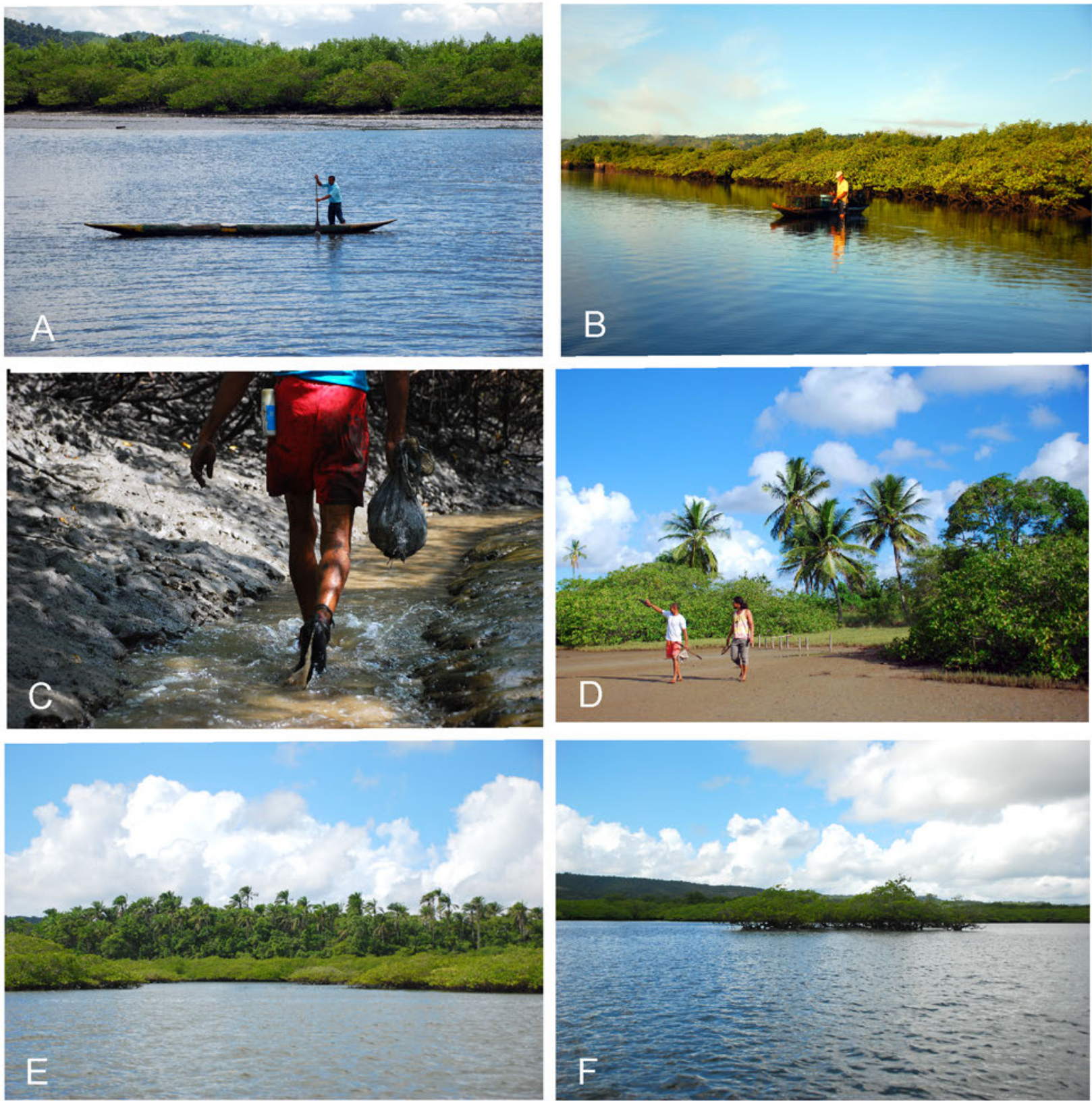

Figura 2. Algumas das principais ecozonas utilizadas pelos pescadores no acesso aos recursos pesqueiros: A- pescador deslocando-se no interior do canal, podendo-se observar zonas de costeiro e de mangue ao fundo; B- pescador de siri na coroa submersa, organizando suas armadilhas; C- "panhador" de caranguejo utilizando um riacho para retornar à canoa; D- pescador em terra, em busca de tocas de guaiamum; E- ilha rodeada de mangue; F- $\underline{\text { ilhote }}$ no interior do canal.

outro e ela fica no meio." Esta zona pode ter vegetação de mangue ou não, sendo assim, costeiros e enseadas podem apresentar coroas, porém estas, diferentemente daqueles, não estão necessariamente próximas à margem. Com base no conhecimento local, nestes bancos que afloram na Baía do Iguape abundam siris-de-coroa e camarões, especialmente o camarão-duro, também conhecido por camarão-coroeiro, por habitar essas ecozonas.

Outros autores (Marques 1991; Mourão 2000; Nishida 2000) também registraram uma unidade de paisagem chamada "croa", descrita por pescadores e marisqueiras em outros estuários do Nordeste (Alagoas e Paraíba), com características similares às coroas da Baía do Iguape. Souto (2010) também faz menção à relação destas com as enseadas quando constituídas de areia ou cascalho. Assim como encontrado por este autor, no Angolá, as coroas foram nomeadas sob critérios faunísticos (e.g., Coroa das Galça, Coroa da Jiboia), personalistas (e.g., Coroa de Zé Branco) e de referência (e.g., Coroa do Maduro de Baixo, Coroa do Maduro de Cima).

Ainda que muitas coroas apresentem vegetação, estas são claramente diferenciadas do "mangue", que 
corresponde a outra ecozona, com grandes áreas compostas por plantas típicas de manguezal [e.g. Avicennia schaueriana Stapf \& Leechm. ex Moldenke, Laguncularia racemosa (L.) C.F.Gaertn., Rhizophora mangle L.], geralmente associadas à margem da baía ("Coroa é rodeada de água; mangue a gente chama quando vai pra terra."), mas não necessariamente, podendo também ser circundado por água. São zonas de intensa extração de caranguejos, aratus e siris-de-mangue pelos pescadores do Angolá. O mangue enquanto unidade de paisagem apresenta-se como uma das mais relatadas na literatura sobre comunidades pesqueiras do Nordeste (Cordell 1974; Marques 1991; CostaNeto 1998; Mourão 2000; Nishida 2000; Souto 2010).

Os mangues no Angolá também podem ser subdivididos em "mangue de areia", "mangue de lama" ou "mangue de barro", de acordo com o substrato predominante. Cada tipo possui suas características peculiares, sendo o "mangue de areia" mais sólido e firme, devido ao sedimento arenoso, permitindo maior facilidade na locomoção. Os mangues "de lama" e "de barro" são mais inconsistentes, exigindo uma caminhada com maior cautela no seu interior.

"[...] areia é porque o mangue é de areia. É misturado com a lama, mas a lama é mais pouca. E mangue de barro é aquele barro grudento, aquela lama braba mermo. E a lama, é essa lama comum que tem no quintal aqui."

"Mangue de areia é raso...não afunda, não, só quando entra bem lá nos mangue."

"Mangue de lama... tem lugar que é alagado, aí cai no buraco e vem lama até no meio do joelho. Tem lama aí fora, no costeiro, que dá na cintura."

"Tem mangue de barro que é lama, que é lama braba, grossa, que você não consegue andar direito."

Essa facilidade em caminhar pelos "mangues de areia", entretanto, não os tornam preferências unânimes, pois outros critérios estão envolvidos nas opções dos pescadores por um dos tipos de substrato, como por exemplo a abundância e qualidade dos recursos almejados. Alves (2004) também registrou a classificação de mangues em "duro" ou "de areia", cujo solo é formado por lama e areia e "mole", com predominância de lama e maior dificuldade na locomoção em relação ao primeiro. Assim como este autor, também foi observado no presente trabalho maior densidade de Rhizophora mangle no sedimento mais lamoso, enquanto que nos "mangues de areia" ocorrem todos os tipos de vegetação, predominando Laguncularia racemosa.

O termo local "terra" caracteriza uma unidade de paisagem diretamente relacionada com a captura do guaiamum, já que tal crustáceo não habita o interior do manguezal. Pode-se, algumas vezes, usar o designativo "mato" para essas áreas, fazendo referência às plantas, em sua maioria gramíneas e rasteiras, embora também encontrese árvores frutíferas: "Lugar certo é em terra. Quando se trata caranguejo, nego diz o mangue. Agora quando se trata guaiamum é em terra. Muitos fala no mato, mas é em terra mesmo, só muda o nome."

Esta ecozona localiza-se próximo às áreas de mangue, sendo com frequência utilizada para acessá-las sem se fazer necessário o uso de embarcação. Por esta razão, quando isto ocorre, é comum utilizar a expressão "por terra". Isso diminui a limitação imposta pela maré no que diz respeito ao horário de retorno para casa: "Quando a maré tá muito tarde, chega em casa quatro, cinco da tarde. Aí eu vou mais por terra." Com frequência, ao falar de áreas para captura do guaiamum, os pescadores se referiram ao termo "Baixa da Ribeira". A "baixa" é uma área de propriedade privada que apresenta relevo mais rebaixado, próxima à comunidade e ao manguezal, onde pescadores adentram, sob permissão do proprietário, para "armar" as armadilhas: "A Baixa [Ribeira] também é lugar bom de armar" ou "Eu só armo ali na Baixa." Contudo, a "Baixa" caracteriza-se como uma localidade dentro da percepção da unidade de paisagem "terra".

Os "rios" são designativos para cursos d'água que, em geral, nascem nos morros para encontrar a baía na região do canal: "O rio, entra água do canal nele e tem água doce que vem de lá de cima." A maré exerce forte influência sobre os rios ampliando seu teor de salinidade, embora alguns, de maior extensão, possam apresentar água mais doce (e.g., Rio Grande, Rio da Ribeira).

Em geral, os pescadores, durante as pescarias, mantêm-se no espaço do canal não adentrando nos rios, utilizando-os mais quando desejam acessar outros sítios de pesca, a exemplo das áreas de mangue mais internas. Não obstante, comumente é feita referência às "bocas de rio", que são as entradas destes a partir do canal: " $O \underline{\text { rio }}$ que tem, a gente nunca entra. Se entrar, entrou no rio Grande. Se ficar ali na boca é a boca do rio." Estas também podem ser compreendidas como ecozonas, ou ao menos zonas de transição relevantes na pesca de camarões, tendo em vista a frequência do seu uso no lance das redes e das citações destes espaços pelos pescadores. É possível que essas áreas garantam maior abundância do recurso devido ao encontro do rio com o canal, porém isto não ficou claro no discurso dos entrevistados. Souto (2010) verificou que as atribuições "rios", utilizadas por pescadores, não se referiam a rios verdadeiros, mas a braços de mar e que esses ambientes eram áreas pouco utilizadas pela comunidade na extração de mariscos e peixes, com grande importância como rota. Entretanto, este autor não fez nenhuma menção às bocas de rio.

Os "riachos" são definidos por terem menor tamanho e largura em relação ao rios: "o riacho é menor e estreito. A gente sobe um pouquinho com a canoa, mas chega em 
cima e já tem os mangue.”, embora não exista uma separação clara entre ambos, já que alguns rios podem ser chamados de riachos nas ocasiões de marés baixas. Durante essas marés, os riachos permanecem com pouca água ou chegam a secar, diferentemente dos rios que nunca ficam sem água. Os riachos são tipicamente utilizados pelos pescadores de siri-açu, que usam essas zonas como acesso às áreas de mangue, onde depositam as armadilhas: "Rio mermo é o que a maré não vaza, riacho é os que a maré vaza... rio mermo aqui é o que? Rio do Reis, Rio Grande, Rio Fundo..."

As "ilhas" são áreas rodeadas por bosques de mangue e/ou por água, e geralmente são habitadas, possuindo uma configuração vegetacional distinta do mangue, com inserção de coqueiros e dendezeiros (Arecaceae), cajueiros e mangueiras (Anacardiaceae), bananeiras (Musaceae), entre outras: "Ilha do Manjubá é como a Ilha de Valtinho, tem gente morando dentro... Só tem coqueiro, dendê, tem muito caju..." ou "ilha tem árvore, não é só mangue." Os "ilhotes" são designativos para ilhas de tamanhos menores ou pequenos agrupamentos de mangue, isolados e susceptíveis a inundações da maré: "Os ilhote é mais solto, é menor." Foram pouco citados e geralmente não são nomeados, provavelmente por serem pouco utilizados.

Algumas áreas de mangue e do canal ao longo da baía apresentam características geomorfológicas diferenciadas, identificadas pelos pescadores como "lajes" e "cascalhos". As "lajes" são formações rochosas de provável origem arenítica que afloram ou tornam-se superficiais em algumas localidades na Baía do Iguape, inclusive dentro dos canais: "[...] Laje, lugar duro.” Os cascalhos são áreas de depósito de conchas de bivalves: "Cascalho é casco de ostra." Comumente, os pescadores relatam a preferência do camarão-duro por ecozonas com esta composição: "[..] ele [camarão-duro] também fica na lama, agora ele gosta mais é de lugar de laje, entendeu? Laje, lugar duro. Mas ele gosta mais de dar naqueles cascalho brabo, lugar duro."; ou "O lugar de laje dá o camarão-duro. Dá mais camarãoduro do que o camarão-branco." Esse é mais um indício de que as características das zonas ecológicas podem ter relação com a abundância de determinados recursos/ espécies e que o conhecimento local destes fenômenos podem otimizar a captura ou mesmo direcionar a atividade para o recurso desejado.

Assim sendo, pôde-se deduzir que alguns recursos pesqueiros estão diretamente associados a determinadas ecozonas, que são utilizadas para acessá-los. Devido a isto, alguns crustáceos recebem nomes relacionados com os ambientes onde comumente podem ser encontrados, a exemplo do camarão-coroeiro, do siri-de-mangue e do siride-coroa. Isto corresponde ao que Marques (1991) chamou de padrão de sobreposição hierárquico-ecológica.

Além do conhecimento das unidades de paisagem, os pescadores demonstraram possuir apropriação integral do espaço, que foi demonstrada através do mapeamento participativo, quando comparado o mapa produzido à imagem de satélite. $\mathrm{O}$ mapa compreendeu a área definida como mais utilizada pelos pescadores de crustáceos da comunidade ("Do Francês [ilha] pra cima é o lugar que a gente pesca mais."), apresentando forte correspondência com a imagem de satélite da Baía do Iguape (Figura 3). Logo, como observado em outras comunidades pesqueiras (CostaNeto 1998; Mourão 2000; Souto 2004, 2010), no Angolá, foi notória uma visão integradora do ecossistema de manguezal e suas ecozonas, compondo um sistema com diversas relações e influências entre a fauna, a flora e a população local que dali tira seu sustento.

Movimentações de elementos da fauna, através de zonas do manguezal, também foram registradas por motivações semelhantes às encontradas por Souto (2004). A saber, tróficas: o guará [Procyon cancrivorus (Cuvier, 1798)], exímio predador do caranguejo, segundo pescadores, que desce da mata para forragear no mangue; ou os siris (Portunidae), que percorrem uma grande área da baía em busca de alimento: "O siri anda o mangue todo... levanta pra comer."; reprodutivas: o guaiamum que sai da terra para desovar no mangue; ou os siris que migram para liberar seus ovos em ambientes mais salinos:"Acho que ela [siri fêmea] desova mais lá pra baixo. Do rio do navio pra baixo."; e abióticas: os camarões e siris que buscam zonas com teor de salinidade mais satisfatório: "o siri, na hora que ele recebe a água doce, ele abate; ele vai mermo pro fundo do canal."

Essa visão ecossistêmica (Souto 2010) também aparece no reconhecimento da dependência e no sentimento de pertencimento, sem uma divisão dicotômica estanque homem-natureza. Para expressar essa percepção mais uma vez é usado o designativo "mangue", porém com uma noção mais ampliada do ambiente:

“O mangue pra mim é tudo, abaixo de Deus é tudo."

"O que significa o mangue pra mim hoje? Pra mim é tudo! Eu dependo dele. Tudo que eu tenho na minha casa foi pertencendo ao mangue. A minha família toda pertence a maré. Se eu dependo dela, é minha vida."

\section{CONSIDERaÇões Finais}

Os pescadores do Angolá entrevistados demonstraram ter um aguçado domínio da espacialidade de todos os pontos de pesca visitados e suas características e uma classificação consistente das ecozonas, relacionandoas aos aspectos bioecológicos dos recursos pesqueiros utilizados. Essa propriedade da dinâmica espacial também foi demonstrada através do mapa produzido a partir dos mapeamentos participativos com pescadores. Esses conhecimentos revelam-se importantes na comunicação entre os pescadores e demonstram ser otimizadores das atividades pesqueiras.

Sitientibus série Ciências Biológicas 11(2): 143-151. 2011. 

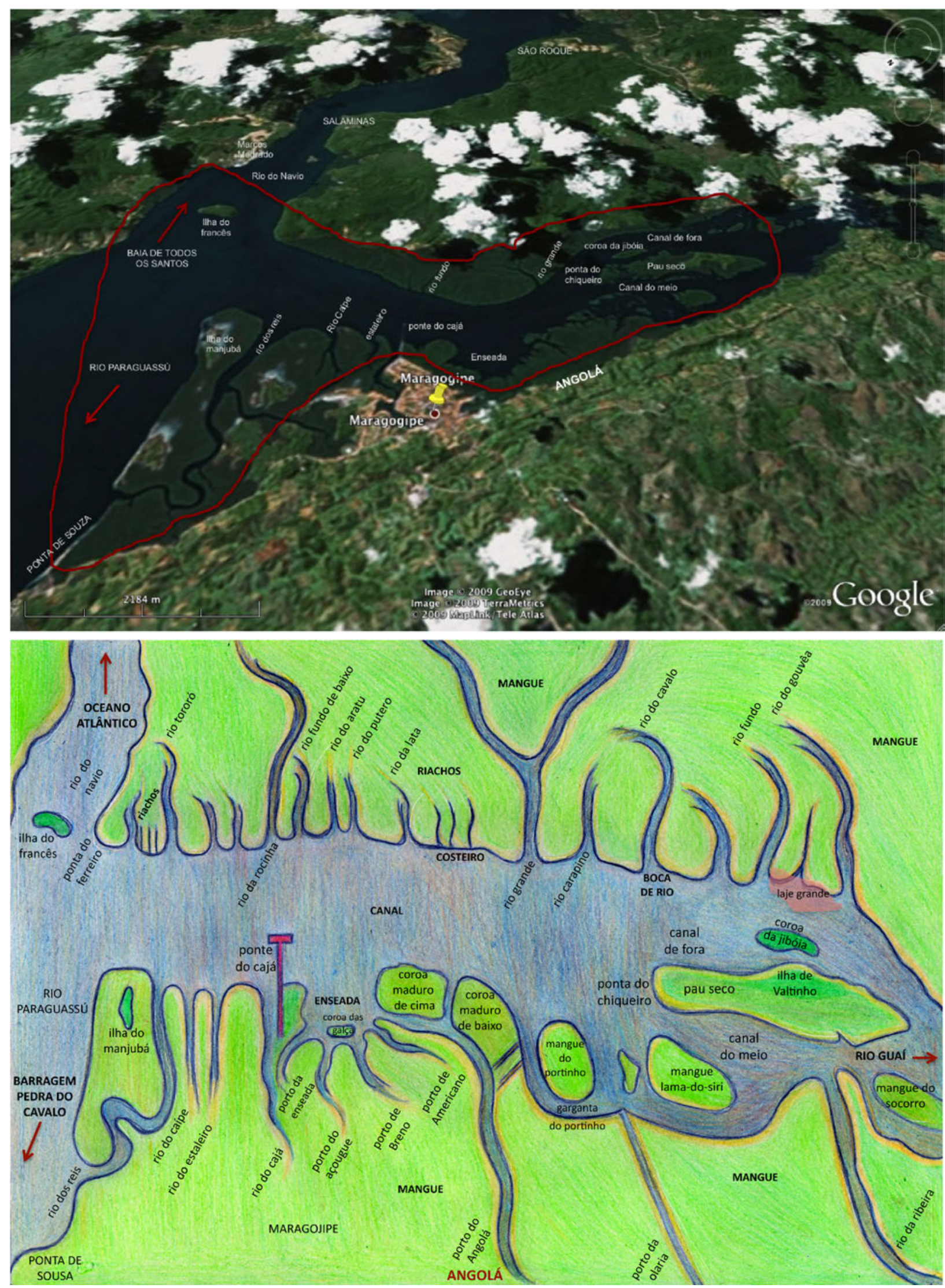

Figura 3. Imagem de satélite de uma parte da Baía do Iguape, com demarcação em vermelho da área de pesca mapeada pelos pescadores (acima) e croqui a partir do mapeamento participativo das principais áreas de uso dos pescadores do Angolá (abaixo). 


\section{REFERÊNCIAS}

Almeida, V.G. 1997. Aspectos da fauna. In: Baía de Todos os Santos: diagnóstico socioambiental e subsídios para a gestão. Gérmen/UFBA-NIMA, Salvador, p. 137-150.

Alves, A. 2004. Os Argonautas do Mangue. Editora UNICAMP, São Paulo.

Amaral, A.C.Z. \& Jablonski, S. 2005. Conservação da biodiversidade marinha e costeira no Brasil. Megadiversidade 1(1): 44-51.

Bahia Pesca 1994. Perfil do Setor Pesqueiro (Litoral do Estado da Bahia). Governo do Estado da Bahia, Salvador.

Bailey, K. 1994. Methods of Social Research. The Free Press, New York.

Begossi, A. 2004. Áreas, pontos de pesca, pesqueiros e territórios na pesca artesanal. In: A. Begossi (org.), Ecologia de Pescadores da Mata Atlântica e da Amazônia. Hucitec, NEPAM/Unicamp, NUPAUB/USP, FAPESP, São Paulo.

Brito, R.R.C. 2001. A gestão da Baía de Todos os Santos. Bahia Análise \& Dados 11(2): 98-100.

Cordell, J. 1974. The lunar-tide fishing cycle in Northeastern Brazil. Ethnology 13(4): 379-392.

Costa-Neto, E.M. 1998. Etnoictiologia, Desenvolvimento e Sustentabilidade no Litoral Norte Baiano: um estudo de caso entre pescadores do município de Conde. Dissertação de Mestrado (PRODEMA). Universidade Federal de Alagoas.

Diegues, A.C.S. 2002. Povos e Águas: inventários de áreas úmidas brasileiras. NUPAUB-USP, São Paulo.

Diegues, A.C.S. 2004. A Pesca Construindo Sociedades. NUPAUB-USP, São Paulo.

Faria, A.A.C. \& Neto, P.S.F. 2006. Ferramentas de Diálogo: qualificando o uso das técnicas do DRP. Ministério do Meio Ambiente, Brasília.

Feleppa, R. 1986. Emics, etics and social objetivity. Current Anthropology 27(3): 243-254.

Fontes, R.F.C; Oliveira, A.J.F.C. \& Pinheiro, M.A.A. 2008. Visão Didática sobre o Meio Ambiente na Baixada Santista. Universidade Estadual Paulista, São Vicente.

Grenier, L. 1998. Working with Indigenous Knowledge: a guide for researchers. International Development Research Centre, Ottawa.

IBAMA (Instituto Brasileiro do Meio Ambiente e dos Recursos Naturais Renováveis) 2000. Decreto da Criação da Reserva Extrativista Marinha da Baía do Iguape. Brasília.

Marques, J.G.W. 1991. Aspectos Ecológicos na Etnoecologia dos Pescadores do Complexo Estuarino-Lagunar MundaúManguaba, Alagoas. Tese de Doutorado. Universidade de Campinas.
Marques, J.G.W. 2001. Pescando Pescadores: ciência e etnociência em uma perspectiva ecológica. 2 ed. NUPAUB/ Fundação Ford, São Paulo.

Mourão, J.S. 2000. Classificação e Ecologia de Peixes Estuarinos por Pescadores do Estuário do Rio Mamanguape - PB. Tese de Doutorado. Universidade Federal de São Carlos.

Nishida, A.K. 2000. Catadores de Moluscos do Litoral Paraibano: estratégias de subsistência e formas de percepção da natureza. Tese de Doutorado. Universidade Federal de São Carlos.

Posey, D.A. 1987a. Introdução “ Etnobiologia: teoria e prática”. In: B. Ribeiro (org.), Suma Etnobiológica Brasileira. Vol. 1 (Etnobiologia). Editora Vozes, Petrópolis, p. 15-25.

Posey, D.A. 1987b. Etnoentomologia de tribos indígenas na Amazônia. In: D. Ribeiro (org.), Suma Etnológica Brasileira. Vol. 1 (Etnobiologia). Editora Vozes, Petrópolis, p. 251-271.

Ramos, M.A.B. 1993. Estudos Geoquímicos Relativamente à Dinâmica de Marés no Estuário Lagunar do Rio Paraguaçu - Bahia - Brasil. Dissertação de Mestrado. Universidade Federal da Bahia.

Ramos, S. 2002. Manguezais da Bahia: breves considerações. Editora da Universidade Estadual de Santa Cruz, Ilhéus.

Santos, C.M. 2008. O Cenário Socioambiental Resultante das Intervenções Humanas no Entorno da Baía do Iguape Bahia. Monografia de graduação. Universidade Federal da Bahia.

Santos, I.M.M \& Santos, R.S. 2008. A etapa de análise no método história de vida - uma experiência de pesquisadores de enfermagem. Texto e Contexto - Enfermagem 17(4): 714719.

Severino-Rodrigues, E.; Soares, F.C.; Graça-Lopes, R.; Souza, K.H. \& Caneo, V.O.C. 2009. Diversidade e biologia de espécies de Portunidae (Decapoda, Brachyura) no estuário de Iguape, Ilha Comprida e Cananéia, São Paulo, Brasil. Boletim do Instituto de Pesca 35(1): 47-60.

Souto, F.J.B. 2004. A Ciência que Veio da Lama: uma abordagem etnoecológica abrangente das relações ser humano/manguezal na comunidade pesqueira de Acupe, Santo Amaro, Bahia. Tese de Doutorado. Universidade Federal de São Carlos.

Souto, F.J.B. 2010. Tudo tem seu lugar: uma abordagem etnoecológica das ecozonas em uma comunidade pesqueira no litoral da Bahia. In: A.G.C. Alves, F.J.B.Souto \& N. Peroni (orgs), Etnoecologia em Perspectiva: natureza, cultura e conservação. NUPEEA, Recife, p. 143-161.

Stebbins, R.A. 1987. Fitting in: the researcher as learner and participant. Quality and Quantity 21:103-108. 